\title{
Steroids: A Diverse Class of Secondary Metabolites
}

\author{
Aeysha Sultan*and Abdul Rauf Raza \\ Department of Chemistry, University of Sargodha, Sargodha-40100, Pakistan
}

\begin{abstract}
Steroids form a group of secondary metabolites having diversity in their structure and biological functions. These natural products, although often linked with the deleterious effect on health, have many medicinal applications and the research is still continued in search of these secondary metabolites as potential lead in drug design/discovery. The Aim of this review is to systematically compile the basic information related to this class of natural products.
\end{abstract}

\section{What are Steroids?}

Steroids are a group of cholesterol derived lipophilic, low-molecular weight compounds found in / derived from a variety of different marine, terrestrial, and synthetic sources. Steroid family includes the sterols, , bile acids [1-4], a number of hormones (both gonadal and adrenal cortex hormones) and some hydrocarbons [5]. All steroid classes and their metabolites play important roles in the physiology and biochemistry of living organisms in which these are found. A number of synthetic steroids are being extensively used as anti-hormones [6], contraceptive drugs [7], anti-cancer agents [8] cardiovascular agents [9], osteoporosis drugs [10] anti-biotics, anesthetics, anti-inflammatories and anti-asthmatics [11].

All steroids are derived from cholesterol and therefore different classes of steroids resemble closely since all of them have the same basic perhydro-1,2-cyclopentenophenanthrene skeleton 1 and a slight variation in this skeleton or the introduction of functional groups result in various classes of steroids.
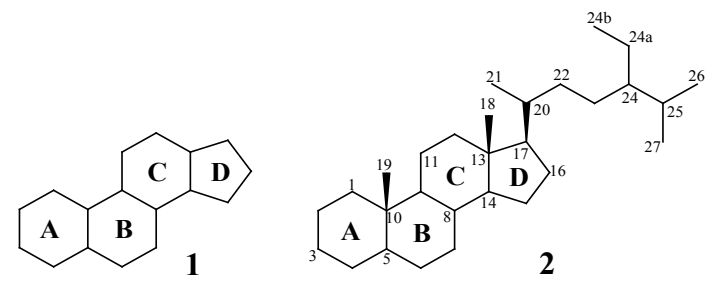

The steroidal nucleus is numbered and rings are lettered as in 2 . With the exception of vitamin $\mathrm{D}$, all steroids possess the skeleton of cyclopenta[a]phenanthrene 1 or a skeleton derived by one or more bond scissions, ring expansions or contractions. Methyl groups are normally present at $\mathrm{C}^{10} \& \mathrm{C}^{13}$ and mostly an alkyl side chain is present at $\mathrm{C}^{17}[12]$.

The structural modifications in the steroid ring system are expressed by certain prefixes for example:

1. The ring contraction by loss of an unsubstituted methylene group is indicated by the prefix nor and for two methylene $\left(\mathrm{CH}_{2}\right)$ groups, dinor-is used. The locant of the lost methylene is followed by the prefix nor-in the nor-compound, e.g., 4-nor-5aandrostane 3 .

2. Ring expansion by inclusion of one methylene group is indicated by the prefix homo, and by two $\mathrm{CH}_{2}$ group dihomo is used. If both addition and removal of $\mathrm{CH}_{2}$ group, both prefixes homo and nor are used in alphabetic sequence, e.g., 4a-Homo-7-nor$5 a$-androstane 4 .

3. The removal of a terminal ring, with addition of a hydrogen atom at each junction atom with the adjacent ring, is indicated by the prefix des, followed by the italic capital letter designating that ring, e.g., des-A-andostrane 5.
4. Fission of a ring, with addition of a hydrogen atom at each terminal group thus created, is indicated by the prefix seco, e.g., 2,3-seco-5a-cholestane 6.

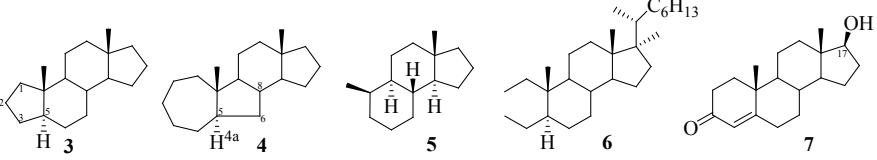

The stereochemistry of steroids reveals them to be non-flat molecules and the hexagonal carbon rings (A to $\mathrm{C}$ ) usually assumes a chair rather than a boat conformation. These are mostly fused in the trans- conformation and the functional groups are oriented either in equatorial or axial position. As a convention, the substituent groups above the plane of the molecule are said to be in the $B$ position, whereas, those present below the plane of the molecule are said to be in the a position. Commonly occurring steroids are usually identified by their trivial names (e.g., cortisol, testosterone, etc.), however, this often leads to confusion in some cases, and the use of systematic (IUPAC) nomenclature is recommended. A complete description of a steroid molecule according to the IUPAC recommended steroidal nomenclature must include the name of the parent compound (pregnane, androstane or estrange, etc.) and number, position and orientation ( $\alpha$ or $\beta)$ of all functional groups. As for instance, the IUPAC name for testosterone (trivial name) will be mentioned as 17ß-hydroxyandrost-4-ene-3-one 7.

\section{Steroidal Biosynthesis}

Although steroids are not triterpenes since these possess C19-C29 skeletons, rather than a C30 skeleton found in the triterpenes but all steroids are derived from the same 30 carbon containing precursor, the squalene 8 from which the triterpenes are derived. The C30 skeleton of squalene 8 is formed by the union of two trans-farnesyl units joined in head to head fashion [13]. It was first isolated from shark liver oil but latter on found to be present in almost all living organisms [14]. The squalene 8 to steroid pathway was mainly explored by Bloch, Lynen, Cornforth and Popjak [15]. The sequence of transformation of squalene 8 into steroid nucleus proceeds via acid catalyzed ring opening of monoepoxide derivative of squalene 8 and involves formation of a

*Corresponding author: Aeysha Sultan, Department of Chemistry, University of Sargodha, Sargodha-40100, Pakistan, Tel: +923222520479; E-mail: blackhawk.aries@gmail.com

Received May 22, 2015; Accepted July 08, 2015; Published July 15, 2015

Citation: Sultan A, Rauf Raza A (2015) Steroids: A Diverse Class of Secondary Metabolites. Med chem 5: 310-317. doi: 10.4172/2161-0444.1000279

Copyright: $\odot 2015$ Sultan A, et al. This is an open-access article distributed under the terms of the Creative Commons Attribution License, which permits unrestricted use, distribution, and reproduction in any medium, provided the original author and source are credited. 
series of carbocationic intermediates [11]. The steric structures of steroids can be rationalized from the possible folding (pseudochair or boat) of polyprenyl chain on the enzyme surface [13].

In animals, squalene 8 is first converted into lanosterol 9 which is further transformed into cholesterol 11. From cholesterol 11, steroidal hormones are synthesized by various pathways. In plants on the other hand, squalene 8 is first converted into cycloartenol 10 from which different phytosterols and other plant steroids are obtained. In fungi and other lower organisms, squalene 8 appears to be first converted into lanosterol 9 but is then converted into ergosterol 12 that is also found in plants [16] (Figure 1).

\section{Classification of Steroids}

Steroid can be grouped according to a number of criteria based on their chemical structure (side chain attached to the ring D), site of production (ovarian or adrenal steroids), biological function (a glucocorticoid or sex steroids) and molecular actions (an estrogenreceptor agonist), or on the basis of biochemical effects $[17,18]$.

On the basis of type of organism in which they are present, the steroids are classified into three broad categories.

1. Insect steroids 2. Vertebrate steroids 3. Plant steroids

\section{Insect steroids or Ecdysteroids}

Ecdysteroids or the insect steroids are polyhydroxy steroids with cis-AB-ring junction. These steroids are actually produced by certain plants (e.g., Cyanotis vaga) and are taken up by the insect during feeding on them; the 20-hydroxyecdysone (ecdysterone or 20-E) 13, is a naturally occurring ecdysteroid hormone.

Ecdysteroids have been found to play a key role in cell proliferation, growth and apoptosis by controlling gene expression involved in ecdysis and metamorphosis in the insects. Ecdysone is one of the most common molting hormones in insects, crabs, and some worms that can disrupt their molting and reproduction [19].

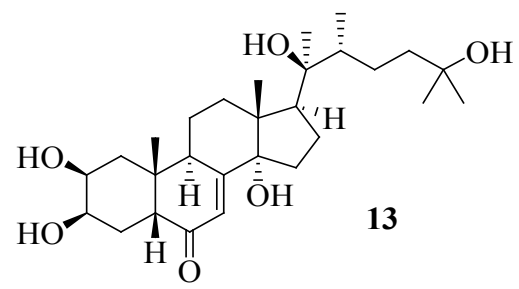<smiles>CC1(C)C2CCC3CC(=O)CC[C@]3(C)C2CC[C@@H]1O</smiles>

These steroids have potential use in promoting muscle growth and fat loss, and have the advantage to lower frequency of side-effects usually associated with anabolic steroids [20]. However their continuous use may cause increased testosterone 7 and dihydrotestosterone (DHT)

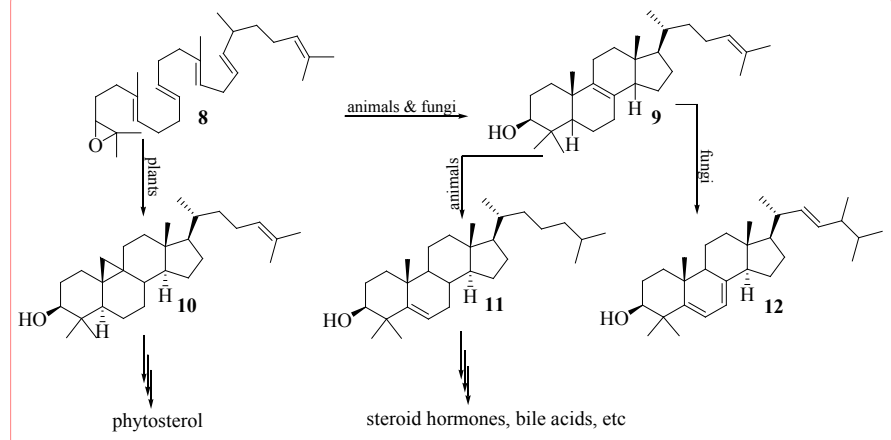

Figure 1: Steroidal biosynthesis [16].
14 production in males, and androgenic changes in females such as increased growth of facial and body hairs and deepening of the voice, as well as gastrointestinal problems for both sexes, such as nausea, bloating, and diarrhea [21]. Certain evidences are there which advocate their use as potential immunomodulator [22].

\section{Vertebrate steroids}

Vertebrate steroids include steroid hormones, cholesterol 11 and the neurosteroids.

Steroid hormones: The hormones are the chemical messengers responsible for specific biological functions. Depending upon the function performed and the site of action, the steroid hormones are categorized as: sex steroids, corticosteroids, anabolic steroids and vitamin D. They are involved in the metabolism of carbohydrates, proteins and fats; help to maintain homeostasis, immune system, maintain blood volume and also control renal excretion of electrolytes. Because of their anti-inflammatory activity (e.g., C60 glucocorticoid) [23], they are effective remedy against arthritis, dermatitis and most importantly they are being used and have been found potent against autoimmune diseases. They act as post-transplantory immunosuppressants to prevent acute transplant rejection and graft versus host disease [24], in addition, they are effective against cancer [25] and heart ailment (e.g., digitoxgenin 15) [24].

The gonadal hormones (estrogens, androgens and progesterones 16) interact with vertebrate androgen or estrogen receptors and play important roles in inducing the body changes known as primary and secondary sex characteristics [26].

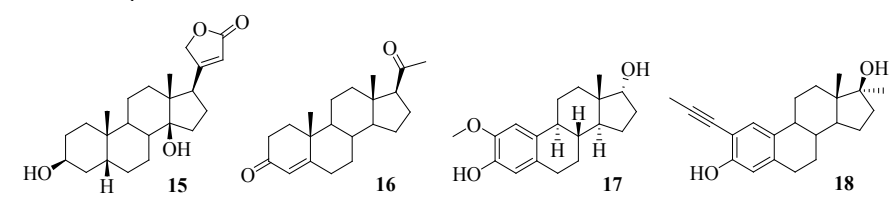

The biological effects of these gonadal hormones are not limited only to reproductive functions, these have other activities as well. As for example, citrate salt of androgenic steroid [27] and certain estrogen derivatives such as 2-methoxyestradiol 17 have tumor growth inhibitory properties. The 2-methoxyestradiol analogues, e.g. 18, [28] estramustane 19 [29] and furanosteroidal antibiotic viridin 20 [30] have been prepared and are being screen for their effects on cell proliferation and cytotoxicity in human cancer cell lines and as inhibitors of tumor cell growth. In addition, estrogen derivatives bearing substituents at $\mathrm{C}^{16}$ and lactones at $\mathrm{C}^{16}$, e.g. 21 [31] have been evaluated as potential estrogenic inhibitors of the $17 \beta$-hydroxysteroid dehydrogenase.
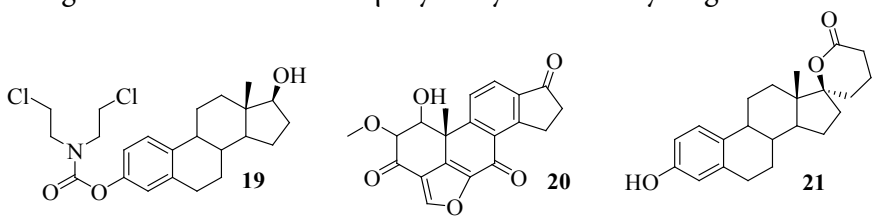

The biological activities of steroids are tremendous and from bioinorganic point of view, these natural products are expected to show increased biological activity upon chelation than the free ligand and evidences are there that support this hypothesis. Keeping this view in mind, many studies have been carried out to synthesize steroidal metal complexes and evaluate their biological activities. Metal based drugs (MBDs) are gaining greater importance with the passage of time because they are specific in their action and have favorable cellular transport properties. For the same reason certain metal complexes of estrogens have been developed as agents for cellular delivery of metal center to estrogen receptors [32]. 
The tin containing steroid derivatives such as triphenyltincholestroyl ether 22 have been prepared and evaluated for use as insecticide, bactericide and fungicide [33]. Steroid hormones labeled with titanium have been synthesized and evaluated for their use in assessing activity of aromatase at various pathologies. High activity of aromatase in endometrium cancer patients without myoma indicates worse prognosis [34]. The organometallic complexes of testosterone 7 and dihydrotestosterone 14 have been prepared and evaluated for their potential use as tracers in non-isotopic carbonyl-metal immuno assay (CMIA) [35]. The $\mathrm{CpRe}(\mathrm{CO})_{3}$ substituted steroids 23 derived from fulvenes have been evaluated as potential radiopharmaceuticals [36]. The $\mathrm{Cu}$ and $\mathrm{Pt}$ complexes of testosterone acetate thiosemicarbazone (TATSC) of the type $\left[\mathrm{M}(\mathrm{TATSC}) \mathrm{CI}_{2}\right](\mathrm{M}=\mathrm{Cu} / \mathrm{Pt})$ have been evaluated against human breast cancer cell [37].

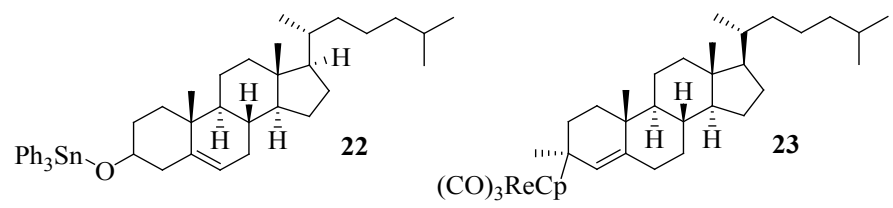

Corticosteroids: These are produced in the adrenal cortex and are involved in a wide range of physiologic systems such as stress response, immune response, regulation of inflammation, carbohydrate metabolism, protein catabolism, behavior and blood electrolyte levels mainly by promoting sodium retention in the kidney. Examples of corticosteroids include cortisol 24 (a glucocarticoid) and aldosterone 25 (a mineralocorticoid).

Synthetic corticosteroids are used in a variety of conditions, ranging from brain tumors to skin diseases. These are used in the treatment of bronchopulmonary dysplasia (BPD) in infants [38], arthritis, temporal arthritis, dermatitis, allergic reactions, asthma, hepatitis, systemic lupus erythematosus, inflammatory bowel disease (ulcerative colitis and Crohn's disease), sarcoidosis and especially for the treatment of eye infections [39]. Synthetic corticosteroid analogues include hydrocortisone (cortisol) 24, fludrocortisone, and dexamethasone 26.
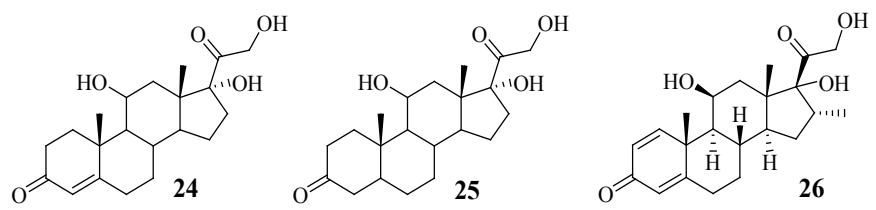

For over 40 years, immunosuppressive drugs have been used for treatment of autoimmune chronic active hepatitis. Glucocorticoids 27 in combination with anti-metabolite azathioprine have been used for the same purpose. Since liver transplant is the only cure for final stage chronic liver disease, some steroids having immunosuppressive properties have been developed that have shown promising results in preventing allograft rejection [40]. Steroids used in combination with cyclosporine and azathioprene have been found effective in reduction of incidence of acute organ rejection and have shown a good safety profile in terms of infection and adverse effects in renal, liver, heart and pancreas transplant [41].<smiles>[R1]c1cc2c3c(ccc2cc1OS(N)(=O)=O)C([R])C([R])C([R])([R])C([R])CC3[R]</smiles>

Long term or excessive use of corticosteroids have been found to be associated with various health risks such as: hyperglycemia, insulin resistance, diabetes mellitus, osteoporosis, anxiety, depression, gastritis, colitis, hypertention, ictus, hypogonadism, hypothyroidism, amenorrhoea and / or retinopathy [42].

Anabolic steroids: These are also known as anabolic-androgenic steroids (AAS) and are a class of steroid hormones related to testosterone 7. They increase protein synthesis within cells, which results in the buildup of cellular tissue (anabolism), especially in muscles. Anabolic steroids also have androgenic and virilizing properties, including the development and maintenance of masculine characteristics such as the growth of the vocal cords and body hair.

These are being used therapeutically in medicine to stimulate bone growth [43], appetite, induce male puberty and treat chronic wasting conditions, such as cancer and AIDS [44]. The fluoxymesterone (also known as halotestin) 28 has strong androgenic properties and is useful for treatment of male hypogonadism and breast neoplasma in women. It tends to exhibit anti-tumor activity by competitive inhibition of prolactin and estrogen receptors [45]. Gestrinone (marketed under the names dimetriose, dimetrose and nemestran) 29 is used for the treatment of endometriosis in many countries but is banned in USA because of its anabolic effects [46].

Anabolic steroids are also responsible for increased muscle mass and physical strength (e.g., desoxymethyltestosterone also called Madol or DMT, 30); however, serious health risks can be produced by longterm use or excessive doses of anabolic steroids. The longer the body's endogenous supply of testosterone is suppressed, the harder it becomes for hypothalamus / pituitary / testicular axis (HPTA) to recover. Longer steroid cycles (typically a cycle lasts 7-14 weeks) are associated with more serious health effects which may include harmful changes in cholesterol levels, acne, high blood pressure, liver damage, dangerous changes in the structure of the left ventricle of the heart, fluid retention, weight gain, hirsutism, voice change and / or hair loss [47]. Some of these effects can be mitigated by exercise or by taking supplemental drugs, however, in extreme cases permanent suppression of HPTA occurs thus necessitating permanent Testosterone Replacement therapy (TRT) [48].
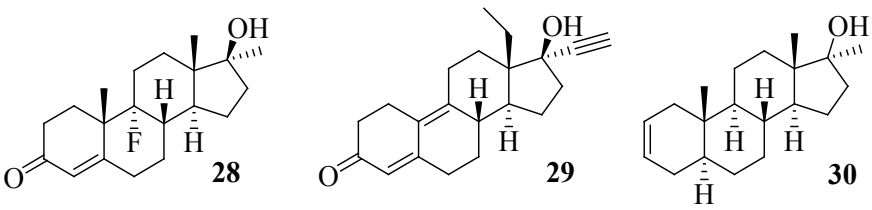

Sterols: These are the steroid alcohols and majority of them appear to be very long lived and are thus not metabolized. Sterols are essential nutrients for the eukaryotes since these plays a vital role in structural integrity of membrane structure of most organisms and control the permeability of ions through the membrane [13].

The cholesterol 11, a sterol, is found in the cell membranes of all tissues and it is transported in the blood plasma of all animals. It is more abundant in the liver, spinal cord and brain and plays a central role in many biochemical processes, such as the composition of cell membranes and the synthesis of steroid hormones [49]. It is involved in the maintenance of biological membranes, formation of bile and acts as a precursor for different steroids and most importantly it is involved in metabolism of fat soluble vitamins. The cholesterol 11 and its derivatives are being traced for their antioxidant properties [50] and cell signaling [51]. Some examples of diseases treated with naturally occurring cholesterol derivatives are allergic reactions, arthritis, some malignancies and diseases resulting from deficiencies or abnormal production of hormones.

The $7 \alpha$ - and $7 \beta$-spermidinyl cholesterol analogues, e.g., 31 have 
been evaluated for their antibacterial and cytotoxic activity [52]. A 7-hydroxysterol 32 from a soft coral has been shown to possess testosterone-5a-reductase inhibitory activity [53]. The radioactive isotope of iodine $\left({ }^{125} \mathrm{I}\right.$ or $\left.{ }^{131} \mathrm{I}\right)$ in 19 -iodocholesterol 33 is used as an adrenal cortex radiocontrast agent for diagnosis of patients suffering from Cushing's syndrome, hyperaldosteronism, pheochromocytoma and adrenalectomy [54].

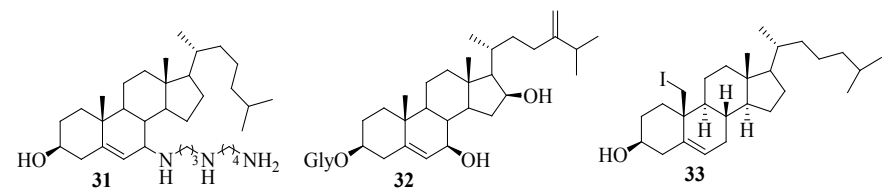

Neurosteroids: Neuroactive steroids (aka neurosteroids) are steroids synthesized in peripheral nervous system (PNS). This class of steroids is useful for treatment of various forms of peripheral neuropathy (e.g., aging, chemotherapy, diabetes, physical injury, etc) [55].

The neurosteroids alter neuronal excitability through interaction with neurotransmitter gated ion channels. These compounds can act as allosteric modulators of neurotransmitter receptors, such as GABA(A), NMDA and sigma receptors. Pregnenolone 34 and progesterone 35 are common representatives of neurosteroids [56]. The neurosteroids plays an important role in the development of nervous system and myelination, inhibition of neuronal toxicity, ischemia and have potential to be an effective therapy for Niemann Pick-type C disease (human childhood fatal neurondegenerative disease) and other lysosomal storage diseases [57]. Progress of aging deeply influence morphological and functional parameters of peripheral nerves due to deterioration of myelin in PNS. The neuroactive steroids are able to reduce aging associated morphological abnormalities of myelin and aging associated myelin fiber loss in sciatic nerves as well [58].

Althesin is an intravenous anaesthetic drug popular for its short duration of action. It is composed of mixture of two neurosteroids, alphadolone 36 and alphaxalone 37 (also known as alphaxalone or alphaxolone). Alphadolone 36 is responsible for the hypnotic effect of althesin; while alfaxalone 37 is responsible for the anesthetic effect and is used in veterinary practice as anesthetic for dogs and cats and has the advantage of less side effects and low plasma elimination half life in these animals. This drug has been withdrawn from market because of its severe side effects alfaxalone 37 , however, has now been re-branded as 'Saffan' for vetenary anaesthsia [59].

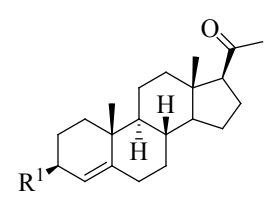

$34 \mathrm{R}^{1}=\mathrm{OH}$ $35 \mathrm{R}^{1}=\mathrm{O}$
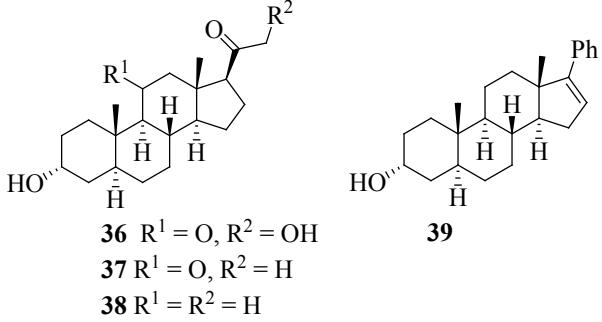

39
Another neurosteroid allopregnanolone (3a,5a-tetrahydroprogesterone or THP) 38 is responsible for neurogenesis and has been found to reverse neuron creation and cognitive deficits in mouse model of Alzheimer's disease [60]. The sedative effects of neurosteroids are counteracted by another steroid 17-phenylandrostenol (17-PA) 39 which binds to GABA(A) receptors, however, 17-PA doesn't block effects of benzodiazepines or bartiturates [14].

Vitamin D and seco-steroids: Vitamin D is classified as a secosteroid in which the 9,10-C/C bond of ring B is broken. Several forms of vitamin $\mathrm{D}$ exists that include vitamin- $\mathrm{D}_{1}, \mathrm{D}_{2}, \mathrm{D}_{3}, \mathrm{D}_{4}$ and $\mathrm{D}_{5}$. The two major forms are vitamin- $\mathrm{D}_{2}$ (ergocalciferol) 40 and vitamin-D3 (cholecalciferol) 41. The vitamin D plays an important role in the maintenance of physiological system, e.g., regulates the $\mathrm{Ca}$ and $\mathrm{P}$ levels in the blood, which is necessary for healthy skeleton system and promotes immunosupression. These are currently being used for the treatment of cancer, tumor, hearing disorder, psoriasis, rickets, asthma, allergy, epilepsy, fancony syndrome [61], osteomalacia and osteoporosis. Physalins, a group of vitamin D isolated from Physalis angulata have been found to have in vitro anti-inflammatory action [62].

The herbasterol 41, a 9,11-seco-sterol isolated from a marine sponge Dysidea herbacea has been screened for ichthyotoxic activity and its analogues $42 \mathrm{a}-\mathrm{e}, 43 \mathrm{a}-\mathrm{c}$ and $44 \mathrm{a}-\mathrm{c}$ isolated from various sources have different biological activities, such as, antihistaminic [63], antiproliferative, antiinflamatory [64] and cytotoxic activity [65-68].
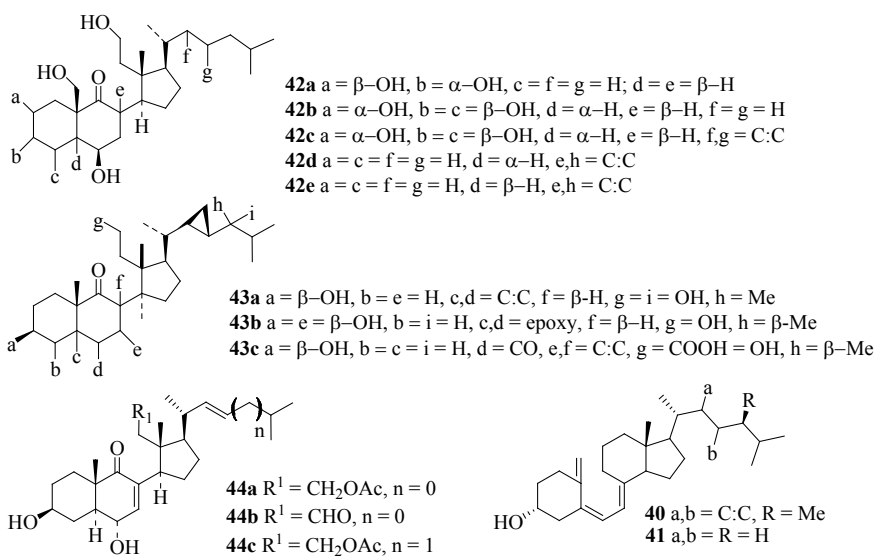

Some new derivatives of 1a,25-dihydroxy-19-nor-vitamin $\mathrm{D}_{3}$ [69] and 2-methylene analogues [64] has been synthesized and found to have tremendous therapeutic potential. As for example, some 2-functionalized analogues of 1a,25-dihydroxyvitamin $\mathrm{D}_{3}$ and $2 \alpha$-( $\omega$-hydroxyalkoxy)-analogues [70] have been shown to be potent inducers of cell differentiation while C(3)-Carbamate 45, amide 46 and sulfoxime 47 derivatives of $1 \alpha, 25$-dihydroxyvitamin $\mathrm{D}_{3}$ have been screened as low affinity vitamin $\mathrm{D}$ receptor; vitamin $\mathrm{D}$ antagonist and as inhibitors of the 24-hydroxylase involved in the catabolism of vitamin D respectively [71-73].

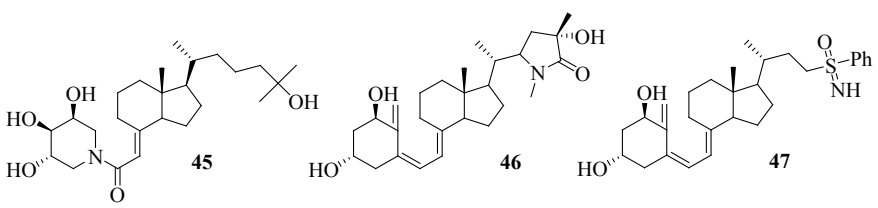

\section{Plant steroids}

Plant steroids are of two broad categories: phytosterols and brassinosteroids.

Phytosterols (also called plant sterols): These are a group of steroid alcohol that occur naturally in plants. They are white powders with mild, characteristic odor, insoluble in water and soluble in alcohols. They have many applications as food additives and in medicine and cosmetics. Phytosterols (e.g., ergosterol 48) have cholesterol-lowering properties [74] and can reduce cholesterol level in human subjects up to $15 \%[75]$ and may act in cancer prevention and these are widely marketed as a dietary supplement [76]. 
<smiles>CC1=C(/C=C\C2=CCCC3(C)C2CC[C@@H]3/C=C/C(C)C(C)C)CCC(O)C1</smiles>

Brassinosteroids: Brassinosteroids (BRs), such as brassinolide 49, have been shown to elicit a broad spectrum of responses including the promotion of cell elongation and cell division, inhibition of deetiolation in the dark, repression of light-regulated genes in the dark and repression of stress-regulated genes [77]. In view of their structural similarities with animal steroids, it has been proposed that BRs might interact with a soluble receptor in order to regulate the expression of specific genes [78]. The BRs tend to counter biotic as well as abiotic stress in plants [79]. Application of BRs to cucumbers results in increased metabolism and removal of pesticides; this property of BRs could be beneficial for reducing the human ingestion of residual pesticides from non-organically grown vegetables [80]. The 24-epibranssinolide (EBL), a brassinolide isolated from Aegle marmelos Correa (Rutaceae), have been found to significantly reduce the maleic hydrazide (MH) induced genotoxicity in Allium cepa chromosomal abberation assay [81], and protect neuronal PC12 cells from 1-methyl-4-phenylpyridinium$\left(\mathrm{MPP}^{+}\right)$induced oxidative stress and apoptosis in dopaminergic neurons [82].

Some $5 a$-hydroxy-6-ketopregnanes 50 have been examined [83] as analogues of brassinosteroid plant growth regulators. The 17 -substituted pregnadienes have been prepared [84] as potential inhibitors of testosterone-5a-reductase. An unusual $\Delta^{20}$-pregnene 51 which was obtained from an octacoral, has been shown to be an inhibitor of the mitochondrial respiratory chain [85].

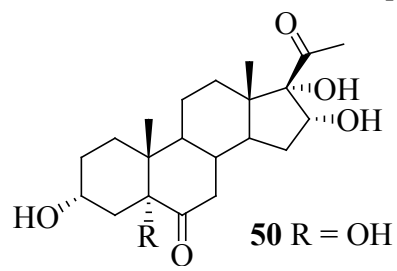<smiles>C=CC1CC(OC(C)=O)C2C3CCC4=CC(=O)C=C[C@]4(C)C3CC[C@]12C</smiles>

\section{Miscellaneous steroids}

Androstane derivatives of general formula 52 have been screened for the treatment and prevention of allergy [86], while the derivatives 53 and 54 have been found to be effective against bone loss, bone fracture, osteoporosis, metastatic bone disease, Paget's disease, periodontal disease, cartilage degeneration, endometriosis, uterine fibroid disease, cardiovascular disease, cerebral degenerative disorder, retenosis, vascular smooth muscle cell proliferation, obesity, inflammatory bowel disease, hypertension, retinal degeneration and cancer especially of breast, uterus, and prostrate [25].

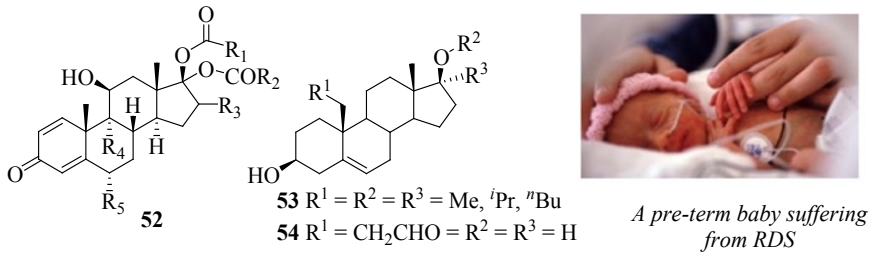

The biggest problem faced by pre-term babies is the difficulty in breathing and many babies develop Respiratory Distress Syndrome (RDS) since their lungs lack a protective film over their air sacs, called the surfactant, which help in oxygen transfer and decrease the energy consumption in breathing process. Various studies have shown that multiple-course steroid treatment given to mothers prior to labor can be effective to increase the survival rate of pre-term babies by forming the protective film over the air sacs and help the fragile babies to get a better chance to survive [87]. Antenatal steroids reduce the chances of hyaline membrane disease and intraventricular hemorrhage and chronic lung disease or death in very low birth weight infants [88].

In addition, steroids exhibit antimutagenic (e.g., stigmasterol 55), [89] anxiolytic, analgesic, anticonvulsant, sedative, hypnotic and anesthetic properties by enhancing GABA receptor function in nongenomic manner [90] and some steroid derivatives 56 have been synthesized as GABA receptor antagonist for the treatment of CNS abnormalities e.g., stress, anxiety, PMS seizures caused by epilepsy and to prevent muscle tension, depression and to induce anesthesia [91].<smiles>CC[C@H](/C=C/[C@H](C)C1CCC2C3CC=C4CC(O)CC[C@]4(C)C3CC[C@@]21C)C(C)C</smiles>

Cardiac glycosides are steroid based drugs used in the treatment of congestive heart failure and cardiac arrhythmia by increasing the force of contraction of heart muscles. In addition to their role in cardiac health, cardiac glycosides have anticancer properties as well [92]. The cardiac glycosides may be classified as cardenolide and /or bufadienolides. A cardenolides is a 23 carbon containing steroids with methyl groups at $\mathrm{C}-10$ and $\mathrm{C}-13$ and a five membered lactone ring at C-17. Bufadienolides have similar structure but with a six membered lactone ring with two double bonds, these constitute an important class highly potent toxins esp. cardiotoxins.

Digoxin (also called digitalis, Lanoxin, Digitek, Lanoxicaps) 57 extracted from Digitalis lanata [93] and ouabain (g-strophanthin) 58 isolated from ripe seeds of African plant Strophanthus gratus and from the bark of Acokanthera ouabaio are cardenolides used in the treatment of various heart conditions [94], however, their use is associated with various health risks such as increased blood pressure (BP) \& tissue perfusion, anorexia, nausea, hallucinations, disorientation, insomnia, impaired yellow color perception and gyenocomastia in males [95]. The ouabain 58 has been used by Somali tribesmen to poison hunting arrows and has been found to exert its toxic effect by blocking the $\mathrm{Na}+$ pump [96] in a fashion similar to one of steroidal alkaloid batrachotoxin isolated from poison arrow frogs [97].

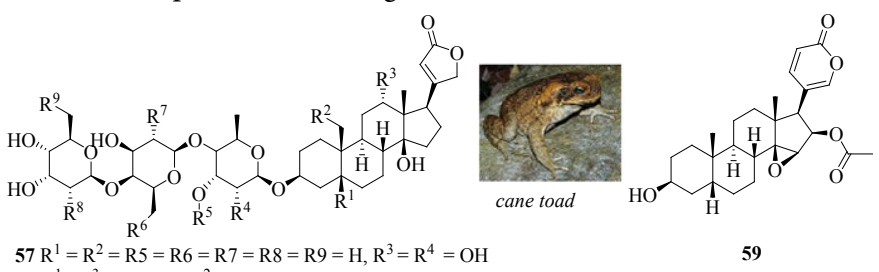
$58 \mathrm{R}^{1}=\mathrm{R}^{3}=\mathrm{R} 4=\mathrm{H}, \mathrm{R}^{2}=\mathrm{O}, \mathrm{R} 5=\mathrm{Me}, \mathrm{R} 6=\mathrm{R} 7=\mathrm{R} 8=\mathrm{R} 9=\mathrm{OH}$

Bufagins (a type of bufodienolides) a constituent of bufotoxins mainly obtained from the secretion of Cane toad (Bufo marinus) when it is injured and or provoked, these secretions are called Toad's milk. Bufagins are also cardiotoxins just like cardenolides but these do have some local anesthetic action [98] and some also have anti-cancer properties against leukemia, melanoma and prostate cancer cells [99]. Certain bufodienolides such as cinobufagin 59 isolated from Chusan island toad (Bufo gargarizans) are used in low doses in traditional Chinese medicines for treatment of atrial fibrillation [100]. 
The steroidal alkaloids represent an important class of alkaloids that contain a perhydro-1,2-cyclopentanophenenthrene nucleus. This class of alkaloids invariable occurs in plant kingdom as glycosidal combination with carbohydrate moieties. The steroidal alkaloids like dihydroplakinamine K 60 from marine sponge Corocium niger have been screened for cytotoxic activity [101]. Another unique class of steroidal alkaloids batrachotoxins 61 isolated from the skins of poison arrow frogs (genus Phyllobates) as well as from the skins and feathers of New Guinea birds (genus Pitohui and Iflita) are extremely potent neurotoxins [102]. Samandarin 62 isolated from the skin glands of fire salamander (Salamandra salamandra) causes muscle convulsions, high blood pressure and hyperventilation in vertebrates [103].
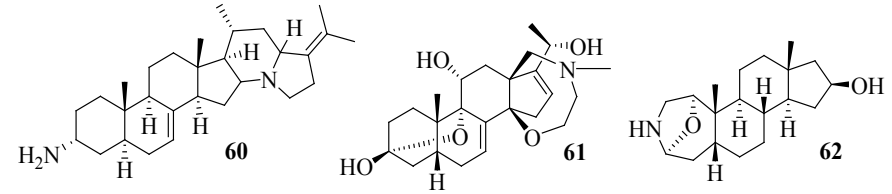

The bile acids are the steroid acids found predominantly in the bile of mammals. These bile acids are made by the cytochrome P450 mediated oxidation of cholesterol in liver from where these are stored in gallbladder conjugated with sulfates or amino acid glycine. Bile acids and their salts are mainly responsible for the emulsification of fats but in addition to this these also regulate the level of cholesterol in body and regulate the population of bacteria in small intestine and in biliary tract. The cholic acid 63 and chenodeoxycholic acid 64 are the most important human bile acids.

Endogenous bile acids act as activators of farnesol $\mathrm{X}$ receptor and play a variety of physiological roles related to the modulation of gene transcription. Some bile acid analogues of mifepristone 65 and 66 have been synthesized as liver selective glucocorticoid antagonists for the treatment of type II diabetes [104].

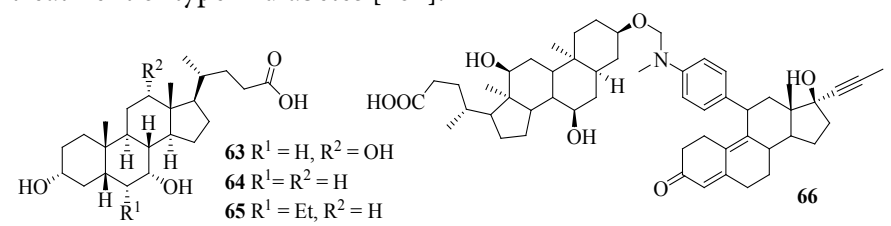

Certain steroidal derivatives have found their use as fluorescent detector for polycyclic aromatic hydrocarbon (PAH), for example, 67 was derived from cholic acid which has a tweezers like structure and has been screened for its use for the detection of PAHs [105]. The cholesteryl benzoate 68 forms cholesteric liquid crystals with helical structures and has applications in thermochromic liquid crystals. Chloesteryl benzoate 68 is also used in hair colors, make-ups and in some cosmetic preparations [106].

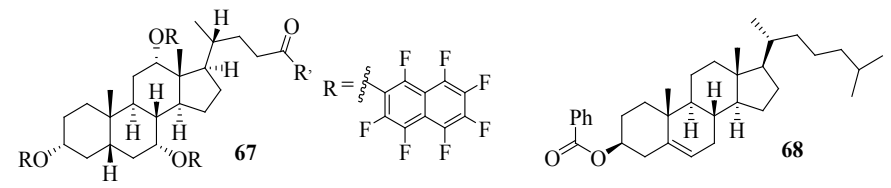

\section{References}

1. Marion F, Coulomb J, Servais A, Courillon C, Fensterbank C, et al. (2006) Radical cascade cyclizations and platinum(II)-catalyzed cycloisomerizations of ynamides 62: 3856-3871.

2. Boeck B De, Harrington-Frost NM, Pattenden G (2005) Tandem cyclisations involving a-ketenyl alkyl radicals. New syntheses of the natural triquinanes pentalenene and modhephene. Org Biomol Chem 3: 340-347.

3. Hitchcock SA, Houldsworth SJ, Pattenden G, Pryde DC, Thomson NM, et al. (1998) A tandem radical macrocyclisation-transannular cyclisation approach towards the taxanes. J Chem Soc Perkin Trans $13181-3206$.
4. Pattenden G, Gonzalez MA, McCulloch S, Walter A, Woodhead SJ (2004) A total synthesis of estrone based on a novel cascade of radical cyclizations. Proc Natl Acad Sci U S A 101: 12024-12029.

5. Balandrin MF, Klocke JA (1998) Medicinal, Aromatic and Industrials Products from Plants: Biotechn. In Agric. and Forest, 4 (Medicinal and Aromatic plants I). Edited by Y.P.S. Bajaj. Springier-Verlag, Berlin, New York.

6. Jovanovic Santa SS, Petri ET, Klisuric OR, Szecsi M4, Kovacevic R, et al. (2015) Antihormonal potential of selected D-homo and D-seco estratriene derivatives. Steroids $97: 45-53$.

7. Lopez LM, Grimes DA, Shulz KF, Curtis KM (2006) Cochrane Database of systematic Reviews 2: 7.

8. Thao NP, Luyen BT, Kim EJ, Kang JI, Kang HK, et al. (2015) Steroidal constituents from the edible sea urchin Diadema savignyi Michelin induce apoptosis in human cancer cells. J Med Food 18: 45-53.

9. Rattanasopa C, Phungphong S, Wattanapermpool J, Bupha-Intr T (2015) Significant role of estrogen in maintaining cardiac mitochondrial functions.. J Steroids Biochem \& Mol Biol 147: 1-9.

10. Emmanuel H, Gauthier M, Emmanuel B, Severine B, Florence C, et al. (2011) Joint Bone Spine 78 (supplement 2), S191-196.

11. Aav R, Kanger T, Pehk T, Lopp M (2005) Unexpected Reactivity of Ethyl 2-(Diethylphosphono)Propionate Toward 2,2-Disubstituted-,3cyclopentanediones. Phosphorus, Sulfur, and Silicon and the Related Elements 180: $1739-1748$.

12. Abd El-Bahaman AA (1991) Biochemical Studies on Steroids, Ph D Thesis, Fac of Agric, Moshtohor Zagazig Univ.

13. St-Onge MP, Lamarche B, Mauger JF, Jones PJ (2003) Consumption of a functional oil rich in phytosterols and medium-chain triglyceride oil improves plasma lipid profiles in men. J Nutr 133: 1815-1820.

14. Melcangi RC, Azcoitia I, Ballabio M, Cavarretta I, Gonzalez LC, et al. (2003) Neuroactive steroids influence peripheral myelination: a promising opportunity for preventing or treating age-dependent dysfunctions of peripheral nerves. Prog Neurobiol 71: 57-66.

15. Bucourt R, Nedlec L, Gasc JC, Weill-Raynal (1969) J Bull Soc Chim Fr 561.

16. Bijoy P, Naik RG, Shivakumar U, Rao GSRS (1994) Total synthesis of ring-A aromatic steroids. J Indian Inst Sci 74: 519.

17. Morgan P, Melinda SM (1997) Kirk Othmer Encyclopedia of Chemical Technology by John Wiley \& Sons 4: 2000.

18. IUPAC Nomenclature of Steroids Revised Tentative Rules (1967) Arch Biochem Biophys 136: 13

19. International Union of Biochemistry, Biochemical Nomenclature and Related Documents (1978) The Biochemical Society, London.

20. Rene L, Karine C, Salwa R, Stanislas V, Anne-Sophie F, et al. (2014) US2014309203A1.

21. IUPAC (1979) Nomenclature of Organic Chemistry, Sections A, B, C, D, E, F and H, 1979 Edition, Pergamon Press, Oxford.

22. Torrsell KBG (1997) Natural Product Chemistry, 2nd Ed., Apotekar societeten Ed, Kristianstads Boktryckeri: Stockholm, 292.

23. Miller WL (2005) Med Prin Pract 14S: 158

24. Thummel CS, Chory J (2002) Steroid signaling in plants and insects--common themes, different pathways. Genes Dev 16: 3113-3129.

25. Chermnykh NS, ShimanovskiÄ NL, Shutko GV, Syrov VN (1988) [The action of methandrostenolone and ecdysterone on the physical endurance of animals and on protein metabolism in the skeletal muscles]. Farmakol Toksikol 51: 57-60.

26. Trenin DS, Volodin VV (1999) 20-hydroxyecdysone as a human lymphocyte and neutrophil modulator: In vitro evaluation. Arch Insect Biochem Physiol 41: 156-161.

27. Werner RA (2005) Massage Therapist's Guide to Pathology. 3rd Ed., Lippincott Williams \& Wilkins, Pennsylvania, USA.

28. Ranke MB, Bierich JR (1986) Treatment of growth hormone deficiency. Clin Endocrinol Metab 15: 495-510.

29. Berger JR, Pall L, Hall CD, Simpson DM, Berry PS, et al. (1996) Oxandrolone in AIDS-wasting myopathy. AIDS 10: 1657-1662. 
30. Schroeder ET, Vallejo AF, Zheng L, Stewart Y, Flores C, et al. (2005) Six-week improvements in muscle mass and strength during androgen therapy in older men. J Gerontol A Biol Sci Med Sci 60: 1586-1592.

31. Olson RE1 (1998) Discovery of the lipoproteins, their role in fat transport and their significance as risk factors. J Nutr 128: 439S-443S.

32. Brown GD (1998) Nat Prod Rep 15: 653.

33. Lebideau F, Percz A, Marrot J, Rager MN, Stephan E, et al. (2001) Tetrahedron 57: 3939.

34. Murugkar A, Unnikrishnan B, Padhye S, Bhonde R, Teat S, et al. (1999) Hormone anchored metal complexes. 1. Synthesis, structure, spectroscopy and in vitro antitumor activity of testosterone acetate thiosemicarbazone and its metal complexes. Met Based Drugs 6: 177-182.

35. Leuscher U, Falk Symp (2000) 114 (Immunology and Liver): 338.

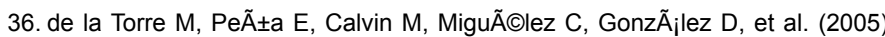
Basiliximab in lung transplantation: preliminary experience. Transplant Proc 37: 1534-1536.

37. Jackson A, Davis J, Pither RJ, Rodger A, Hannon MJ (2001) Estrogen-derived steroidal metal complexes: agents for cellular delivery of metal centers to estrogen receptor-positive cells. Inorg Chem 40: 3964-3973.

38. Bassler D1 (2015) Inhalation or instillation of steroids for the prevention of bronchopulmonary dysplasia. Neonatology 107: 358-359.

39. Smith LL1 (1991) Another cholesterol hypothesis: cholesterol as antioxidant. Free Radic Biol Med 11: 47-61.

40. Chadha MS (1994) J Biol Phys 20: 95

41. Harrison DM (1985) Nat Prod Rep 2: 543.

42. Coopman S, Degreef H, Dooms-Goossens A (1989) Identification of crossreaction patterns in allergic contact dermatitis from topical corticosteroids. $\mathrm{Br}$ J Dermatol 121: 27-34.

43. Haines TH1 (2001) Do sterols reduce proton and sodium leaks through lipid bilayers? Prog Lipid Res 40: 299-324.

44. Pinna G, Costa E, Guidotti A (2006) Fluoxetine and norfluoxetine stereospecifically and selectively increase brain neurosteroid content at doses that are inactive on 5-HT reuptake. Psychopharmacology (Berl) 186: 362-372.

45. Seth R (2009) Anabolic pharmacology.

46. Roy SN, Bhattacharya S (2004) Drug Safety: An International Journal of Medical Toxicity and Drug Experience, 27: 75.

47. Diel P, Friedel A, Geyer H, Kamber M, Laudenbach-Leschowsky U, et al. (2007) Characterisation of the pharmacological profile of desoxymethyltestosterone (Madol), a steroid misused for doping. Toxicol Lett 169: 64-71.

48. Ostlund RE Jr, Racette SB, Stenson WF (2003) Inhibition of cholesterol absorption by phytosterol-replete wheat germ compared with phytosteroldepleted wheat germ. Am J Clin Nutr 77: 1385-1389.

49. De Stefani E, Boffetta P, Ronco AL, Brennan P, Deneo-Pellegrini H, et al. (2000) Plant sterols and risk of stomach cancer: a case-control study in Uruguay. Nutr Cancer 37: 140-144.

50. Szekeres M, Nemeth K, Koncz-Kalman Z, Mathur J, Kauschmann A, et al (1996) Brassinosteroids rescue the deficiency of CYP90, a cytochrome P450, controlling cell elongation and de-etiolation in Arabidopsis. Cell 85: 171-182.

51. Takatsuto S (1994) J Chromatogr 658: 3

52. Liu R, Wenxin L (2002) Faming Zhuanli Shenqing Gongkai Shoumingshu 1: 167.

53. Gower DB (1984) Biochemistry of Steroid Hormones, Makin, H. J. L., Ed Blackwell scientific publications: London, 117.

54. Counsell RE, Ranade VV, Blair RJ, Beierwaltes WH, Weinhold PA (1970) Steroids 317.

55. Silvia G, Simone R, Marzia P, Gaia C, Nico M, et al. (2015) Neuroactive steroids and the peripheral nervous system: An update. Steroids.

56. Blizzard TA, Gude CM, Jerry A (2005) WO 5,972.

57. Fotherby K (1984) Biochemistry of Steroid Hormones, Makin, H. J. L., Ed Blackwell scientific publications: London, 207.

58. Mellado GG, Zubia E, Ortega MJ, Lopez-Gonzalez PJ (2005) Steroids from the Antarctic octocoral Anthomastus bathyproctus. J Nat Prod 68: 1111-1115.

59. Wang JM, Singh C, Liu L, Irwin RW, Chen S, et al. (2010) Allopregnanolone reverses neurogenic and cognitive deficits in mouse model of Alzheimer's disease. Proc Natl Acad Sci USA 107: 6498-6503.

60. Kelley SP, Alan JK, O'Buckley TK, Mennerick S, Krishnan K, et al. (2007) Antagonism of neurosteroid modulation of native gamma-aminobutyric acid receptors by (3alpha,5alpha)-17-phenylandrost-16-en-3-ol. Eur J Pharmacol 572: 94-101.

61. Dopseso J, Quinoa E, Riguera R, Debitus C, Bergquist PR (1994) Tetrahedron 50: 3818.

62. He H, Kulanthaivel P, Baker BJ, Kalter K, Darges J, et al. (1995) Tetrahedron 51: 51.

63. Morris LA, Christie EM, Jaspars M, van Ofwegen LP (1998) A bioactive secosterol with an unusual A- and B-ring oxygenation pattern isolated from an Indonesian soft coral Lobophytum sp. J Nat Prod 61: 538-541.

64. Aiello A, Esposito G, Fattorusso E, luvone T, Luciano P, et al. (2003)Aplidiasterols $A$ and $B$, two new cytotoxic 9,11 -secosterols from the Mediterranean ascidian Aplidium conicum. Steroids 68: 719-723.

65. Migliuolo A, Piccialli V, Sica D (1992) Two new 9,11-secosterols from the marine sponge Spongia officinalis. Synthesis of 9,11-seco-3 beta, 6 alpha,11trihydroxy-5 alpha-cholest-7-en-9-one. Steroids 57: 344-347.

66. Lopp A, Pihlak A, Paves H, Samuel K, Koljak R, et al. (1994) The effect of 9,11-secosterol, a newly discovered compound from the soft coral Gersemia fruticosa, on the growth and cell cycle progression of various tumor cells in culture. Steroids 59: 274-281.

67. Salhab WA, Hynan LS, Perlman JM (2003) Partial or complete antenata steroids treatment and neonatal outcome in extremely low birth weight infants $<$ or $=1000 \mathrm{~g}$ : is there a dose-dependent effect? J Perinatol 23: 668-672.

68. Lim JC, Park JH, Budesinsky M, Kasal A, Han YH, et al. (2005) Antimutagenic constituents from the thorns of Gleditsia sinensis. Chem Pharm Bull (Tokyo) 53: $561-564$

69. Belelli D, Lambert JJ (2005) Neurosteroids: endogenous regulators of the GABA(A) receptor. Nat Rev Neurosci 6: 565-575.

70. Calogeropolous T, Tsotinus A, Souli C, Makriyannis A (2002) PCT Int Appl WO 0253577.

71. Ridley CP, Faulkner DJ (2003) New cytotoxic steroidal alkaloids from the Philippine sponge Corticium niger. J Nat Prod 66: 1536-1539.

72. Holm RH, Kennepohl P, Solomon El (1996) Structural and Functional Aspects of Metal Sites in Biology. Chem Rev 96: 2239-2314.

73. Mann J (1987) Secondary Metabolism, 2nd Ed., Calrendon press, Oxford

74. Banthorpe DV (1994) Natural Products: their Chemistry and Biological Significance, 1st Ed., Longman scientific and technical, Essex 289.

75. Vieira AT, Pinho V, Lepsch LB, Scavone C, Ribeiro IM, et al. (2005) Mechanisms of the anti-inflammatory effects of the natural secosteroids physalins in a model of intestinal ischaemia and reperfusion injury. Br J Pharmacol 146: 244-251.

76. Delvin M T (2002) Text Book of Biochemistry with Clinical Correlations, 5th Ed.

77. Schwarz S, Mueller G, Osemund D, Richter M, Petus O, et al. (2003) US $65,83,130$.

78. Sharma P, Bhardwaj R, Arora HK, Arora N (2008) Biol Plant 52: 767.

79. Xia XJ, Zhang Y, Wu JX, Wang JT, Zhou YH, et al. (2009) Brassinosteroids promote metabolism of pesticides in cucumber. J Agric Food Chem 57: 84068413.

80. Sondhi N, Bhardwaj R, Kaur S, Singh B, Kumar N (2008) Plant Growth Regul 54: 217

81. Howell A, Buzdar A (2005) Are aromatase inhibitors superior to antiestrogens? J Steroid Biochem Mol Biol 93: 237-247.

82. Julie C, Fanny L, Benoit D, Maria-Grazia MJ (2011) 24-Epibrassinolide, Phytosterol from the Brassinosteroid Family, Protects Dopaminergic Cells against MPP+-Induced Oxidative Stress and Apoptosis. Toxicol 392859

83. Biggadike K, Morton GE (2003) WO 0362,259

84. Mellon S, Gong W, Griffin LD (2004) Niemann pick type C disease as a mode for defects in neurosteroidogenesis. Endocr Res 30: 727-735. 
85. Meggers E1 (2007) Exploring biologically relevant chemical space with metal complexes. Curr Opin Chem Biol 11: 287-292.

86. Sanjiv BA, Mark O, Ann E, Matthew M, Christy M, et al. (2010) J Pediatrics 156: 377.

87. Chohan ZH, Arif M, Akhtar MA, Supuran CT (2006) Metal-Based Antibacterial and Antifungal Agents: Synthesis, Characterization, and In Vitro Biological Evaluation of $\mathrm{Co}(\mathrm{II}), \mathrm{Cu}(\mathrm{II}), \mathrm{Ni}(\mathrm{II})$, and $\mathrm{Zn}(\mathrm{II})$ Complexes With Amino AcidDerived Compounds. Bioinorg Chem Appl .

88. Singh K, Singh DP, Barwa MS, Tyagi P, Mirza Y (2006) Some bivalent metal complexes of Schiff bases containing $\mathrm{N}$ and $\mathrm{S}$ donor atoms. J Enzyme Inhib Med Chem 21: 749-755.

89. Chohan ZH, Supuran CT, Scozzafava A (2004) Metalloantibiotics: synthesis and antibacterial activity of cobalt(II), copper(II), nickel(II) and zinc(II) complexes of kefzol. J Enzyme Inhib Med Chem 19: 79-84.

90. Paschke R, Paetz C, Mueller T, Schmoll HJ, Mueller H, et al. (2003) Biomolecules linked to transition metal complexes--new chances for chemotherapy. Curr Med Chem 10: 2033-2044.

91. Hollman A (1996) Drugs for atrial fibrillation. Digoxin comes from Digitalis lanata. Brit Med J 312: 912.

92. Laurie M, Erika V, Sandy A, Isabelle M, Yuting M, et al. (2012) Science Translational Medicine 4: 143-199.

93. Goodman DJ, Rossen RM, Cannom DS, Rider AK, Harrison DC (1975) Effect of digoxin on atioventricular conduction. Studies in patients with and without cardiac autonomic innervation. Circulation 51: 251-256.

94. Pierog JE, Kane KE, Kane BG, Donovan JW, Helmick T (2009) Tricyclic antidepressant toxicity treated with massive sodium bicarbonate. Am J Emerg Med 27: 1168
95. Gao J, Wymore RS, Wang Y, Gaudette GR, Krukenkamp IB, et al. (2002) Isoform-specific stimulation of cardiac $\mathrm{Na} / \mathrm{K}$ pumps by nanomolar concentrations of glycosides. J Gen Physiol 119: 297-312.

96. Schneider R, Ralf V, Manfred N, Wolf DL, Ulrike K, et al. (1998) Bovine Adrenals Contain, in Addition to Ouabain, a Second Inhibitor of the Sodium Pump. J Bio Chem 273: 784-792.

97. Wang G, Sun G (1994) J Tradit Chin Med 14: 132.

98. Jiun Y, William JH, Shu K, Paulus SW (2002) Effects of bufalin and cinobufagin on the proliferation of androgen dependent and independent prostate cancer cells. Prostate 54: 112-124.

99. Bick RJ, Poindexter BJ, Sweney RR, Dasgupta A (2002) Effects of Chan $\mathrm{Su}$, a traditional Chinese medicine, on the calcium transients of isolated cardiomyocytes: cardiotoxicity due to more than $\mathrm{Na}$, K-ATPase blocking. Life Sci 72: 699-709.

100. Cardarelli NF, Kanakkanatt SV (1983) US 4,634,693.

101. Enev VS, Mohr J, Harre M, Nikisch K (1998) Tetrahedron-Asymmetr 9: 2693. 102. Schopf C, Koch K (1942) Liebigs Ann Chem 552: 37.

103. Philomin V, Vessieres A, Gruselle M, Jaouen G (1993) Synthesis of cobalt carbonyl complexes of cortisol and testosterone. Study of their recognition by specific polyclonal antibodies. Bioconjug Chem 4: 419-424.

104. Cano-Lerida L, Walton P, Rose M, Tarbin J (2005) PCT Int Appl 1: 74.

105. Simon M, Harwood KJ, Toyne J, Goodby W, Michael P (1999) The Synthesis of $3 \alpha-/ 3 \beta$ - Cholesteryl and Cholestanyl Esters and Ethers - an Assessment of their Mesogenicity. Mol Cryst Liq Cryst 332: 485-495.

106. Sevillano LG, Caballero E, Tome F, Medarde M, San Feliciano A (2002) Tetrahedron 58: 10103 